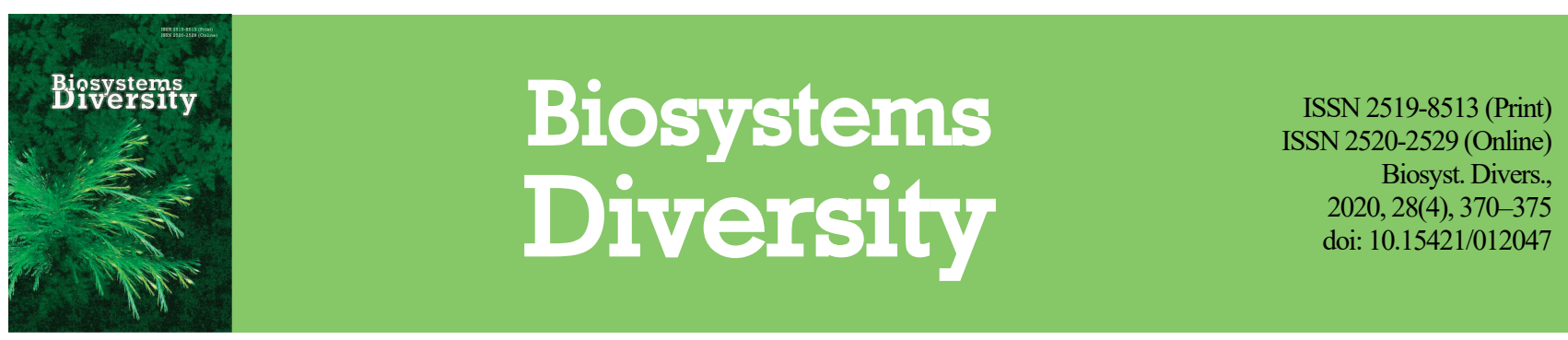

\title{
Cuticular wax composition of mature leaves of species and hybrids of the genus Prunus differing in resistance to clasterosporium disease
}

\author{
N. O. Khromykh, Y. V. Lykholat, A. A. Anishchenko, O. O. Didur, A. A. Gaponov, A. M. Kabar, T. Y. Lykholat \\ Oles Honchar Dnipro National University, Dnipro, Ukraine
}

Article info

Received 29.09.2020

Received in revised form 04.11.2020

Accepted 07.11.2020

Oles Honchar Dnipro National University, Gagarin av., 72,

Dnipro, 49010, Ukraine. Tel: $+38-050-487-87-17$ E-mail:

khromykhn@ukr.net

\begin{abstract}
Khromykh, N. O., Lykholat, Y. V., Anishchenko, A. A., Didur, O. O., Gaponov, A. A., Kabar, A. M., \& Lykholat, T. Y. (2020). Cuticular wax composition of mature leaves of species and hybrids of the genus Prunus differing in resistance to clasterosporium disease. Biosystems Diversity, 28(4), 370-375. doi:10.15421/012047
\end{abstract}

The interaction of a host plant with pathogen implies an extremely complex process involving the outer waxy layer of the cuticle, cutin, cell membrane, and intracellular structures. However, the initial contact between plants and pathogens takes place in cuticular waxes covering the surface of leaves, stems and fruits. Despite many findings on the role of plant epicuticular waxes, there is a gap in the understanding of the relationship between individual compounds and their functions. The pathogenic fungus Clasterosporium carpohilum (Lev.) Aderh. parasitizes the tissues of many stone fruit trees, damaging leaf and fruit surface. The aim of this work was to find out if the quantity and composition of leaf epicuticular wax could be responsible for the resistance to clasterosporium disease. The study of differences of plants in fungal resistance was carried out on species and hybrids of the genus Prunus from the collection of the Botanical Garden of Oles Honchar Dnipro National University (Dnipro city, Ukraine). The chloroform extracts of epicuticular waxes from the surface of mature leaves were analyzed by gas chromatography connected to mass-spectrometry. GC/MS assay was performed using Shimadzu GCMS-QP 2020 El equipped with capillary column ( $5 \%$ diphenyl/95\% dimethyl polysiloxane), and helium as a carrier gas. Mass Spectrum Library 2014 for GSMS was used to identify the separated compounds of the wax extracts. The maximum total wax amount on the adaxial and abaxial leaf surface of hybrid 2 was twice the minimum wax accumulation for hybrid 4. Overall, 20 individual compounds belonging to six hydrocarbon classes were identified. Leaf epicuticular wax composition both in Prunus persica (L.) Batsch and P. dulcis (Mill.) D. A. Webb, and hybrids was dominated by long-chain n-alkanes with even carbon number (77.6-90.9\% of total sum). The alkenes' class was represented only by 17-pentatriacontene detected in the wax of both Prunus species. Octadecanaldehyde was found in epicuticular wax of $P$. dulcis while absent in wax of the more resistant species $P$. persica. Prime alcohols 1-tetradecanol and 1-hexacosanol were detected in leaf waxes of hybrid 4 and $P$. dulcis respectively. The ester class contained seven compounds found in leaf epicuticular waxes of both plant species and all hybrid forms. The identification of phthalic acid esters in leaf wax extracts was unexpected, and the phthalates' origin is discussed. Strong positive correlation between leaf damage and tetrapentacontane content in epicuticular waxes could presumably be the result of infection-induced metabolism reprogramming in epidermal cells of infected leaves.

Keywords: peach; almond; epicuticular wax; n-alkane; aldehyde; fungal damage; resistance.

\section{Introduction}

The plant cuticle is a complexly arranged outer layer of the cell wall that emerged during evolution as one of the most important adaptations of plant organisms to the air environment. Cuticle is a hydrophobic structure composed of insoluble polyester cutin and the outer soluble layer of cuticular waxes. Waxes mainly comprise very long chain fatty acids and their derivatives such as aldehydes, alkanes, secondary alcohols, ketones, primary alcohols, and esters. Of these waxes, intracuticular wax is embedded in cutin polymer while epicuticular wax accumulates on the outer surface of the cuticle (Lee \& Suh, 2015). Triterpenoids and other cyclic compounds, as well as the primary alcohols, preferentially accumulate within the intracuticular wax, whereas a mixture of long-chain aliphatic molecules including free fatty acids and alkanes in many cases accumulate in the epicuticular layer (Buschhaus et al., 2007; Jetter \& Riederer, 2016). The cuticle is involved in many vital physiological processes in plants, including control of non-stomatal water loss and gas exchange (Lee \& Suh, 2015), prevention of overheating by the formation of leaf surface require reflectivity (Koch \& Ensikat, 2008; Lykholat et al., 2018), selfcleaning of leaves (Wen et al., 2006), fruit development and ripening (Trivedi et al., 2019), protection against the attacks of insects (Bohinc et al., 2014; Braccini et al., 2015; Rebora et al., 2020) and pathogens (Laźniewska et al., 2012). The interaction between host plant and pathogenic fungi implies an extremely complex process involving the outer waxy layer of the cuticle (Bohinc et al., 2014), cutin (Sharma et al., 2018), cell membrane and intracellular structures (Zabka et al., 2008). It has been established that fungal pathogens destroy plant cuticle by enzymatic degradation; however, cutin monomers released during the hydrolysis of polymer cutin can act as activators of plant defense reactions (Yeats \& Rose, 2013). Lipase Lip1, secreted by the fungus Blumeria graminis (DC.) Speer to the cell surface, releases alkanes and primary fatty alcohols from epicuticular wax of wheat leaves, which contributes to pathogen development (Feng et al., 2009). Various components of plant cuticle and the cellular metabolites were reported as the markers of infection (Batovska et al., 2009; Agudelo-Romero et al., 2015). Some of these compounds were characterized as a possible cue for triggering the fungus conidial germination and differentiation (Hansjakob et al., 2011), others, on the contrary, as the compounds associated with the resistance of different plant species to pathogenic action (Nanni et al., 3013; Calvo-Garrido et al., 2014; Sivankalyani et al., 2016). Without disputing the important role of cutin as a physical barrier to infection, it should be recognized that the initial contact between the plants and pathogens is carried out by cuticular waxes on the surface of leaves, stems and fruits (Gniwotta et al., 2005). The wide variety of research data on the role of cuticular waxes of different plant species in providing resistance or sensitivity to pathogens makes it difficult to establish a clear relationship between individual wax components and functions (Buschhaus \& Jetter, 2012). Sharma et al. (2018) points out the ambiguity of the functions of long-chain fatty acids that are 
present in plant surface waxes and can facilitate fungal infection or initiate defense mechanisms against pathogens. The in vitro tests carried out by Ding et al. (2020) showed that mycelial growth of Penicillium digitatum (Pers.) Sacc. could be promoted by the epicuticular wax of mandarin fruit cuticle, while conidial germination could be inhibited by cutin.

Fungal plant pathogens are in many ways specialized and adapted to infect and exploit their host plants (Niks \& Rubiales, 2002). The stone fruit species of the Prunus genus, which are economically important crops in many regions, also are susceptible to fungal diseases that reduce yield and quality. In India, as Dar et al. (2017) reported, a serious problem for Prunus armeniaca L. and $P$. persica (L.) Batsch was caused by the plant pathogenic species Stigmina carpophila (Lév.) M. B. Ellis, many attacking plant fruit and foliage; appearance of dark brown leaf spots resulted in premature defoliation, which led to a decline in the fruit production by almost 30\%. A pathogenic fungus Clasterosporium carpohilum Lev. Aderh., is the causative agent of clasterosporium disease, which often damages the leaves of stone fruit trees in Ukraine, including $P$. persica and $P$. dulcis (Mill.) D. A. Webb. It has already become apparent that the intensive use of antibacterial and antifungal drugs has dramatically increased the microbial resistance (Zacchino et al., 2017). At the same time, efforts aimed at the stimulating plant development (Shcherbyna et al., 2017; Nazarenko et al., 2019; Palchykov et al., 2019) or identifying the markers of innate plant resistance to pathogens and their combination in hybrid forms (Nazarenko et al., 2018) can be effective. The objective of the study was to reveal the components of leaf epicuticular waxes' composition of species and their hybrids of the genus Prunus, which could be associated with plant resistance to clasterosporium disease.

\section{Materials and methods}

The study was carried out during July-August 2020 at the Botanical Garden of Oles Honchar Dnipro National University (Baranovski et al., 2016; Zazharskyi et al., 2020). Plant material was taken from fruit trees included in the collection, namely $P$. persica, $P$. dulcis and some hybrid forms, created by the researchers of Nikitsky Botanical Garden (National Academy of Agrarian Science of Ukraine) and DNU Botanical Garden (Table 1). Pathogen Clasterosporium carpohilum Lev. Aderh. is a microscopic imperfect fungus that parasitizes the tissues of higher plants, mainly fruit trees. Spores fall on young leaves, affecting them, while the fungus does not spore on leaves. The sensitivity of $P$. persica, $P$. dulcis and their hybrids to clasterosporium disease was assessed in accordance with known approaches (Azmi \& Korra, 2010; Dar et al., 2017) taking into account the healthy and infected leaf area of each of fruit plants. For this, the number and diameters of holes that appeared due to infection were determined on leaves selected at random (30 leaves in three repetitions for each tree). Then, leaf area was measured using software product Easy Leaf Area Free 1.02 for OS Android. The proportion of the damaged area expressed as a percentage of the total leaf area was the basis for establishing the damage class. In our study, the scale had such a gradation: no holes class $0 ; 0-1 \%$ of leaf area damaged - class $1 ; 1-5 \%$ of area damaged class $2 ; 5-10 \%$ of area damaged - class $3 ; 10-25 \%$ of leaf area damaged class 4 , and more than $25 \%$ of area damaged - class 5 (Table 2 ).

Plant leaves were harvested from 1-3 trees of each species during the full development of the leaf blade (in July) in sunny weather in the middle of the day. Plant material was immediately delivered to the laboratory and subjected to extraction of the epicuticular waxes from the leaf surface with chloroform (Buchhaus et al., 2007). Both adaxial and abaxial leaf surface were subjected to the extraction. Briefly, cut leaf fragments having an area of $2-4 \mathrm{~cm}^{2}$ (depending on leaf area) were prepared, avoiding major leaf veins. Each of the fragments was in turn immersed for 30 seconds in a bottle containing chloroform $(10 \mathrm{~mL})$, after which the total extract was filtered into a flask and dried in a stream of nitrogen. The wax amounts was calculated by the gravimetric method, taking into account the difference in the flask weight with dried extract and clean flask weight, and expressed in $\mu \mathrm{g}$ per unit leaf area.

The capillary gas chromatography connected to mass-spectrometry assay was applied to study component composition of the epicuticular waxes from the adaxial and abaxial surface of the mature leaves of the genus Prunus. GC/MS analysis of the chloroform wax extracts was performed using Shimadzu GCMS-QP 2020 El equipped with Rxi-5ms column $(30 \mathrm{~m} \times 0.25 \mathrm{~mm}$, film thickness $0.25 \mu \mathrm{m}, 5 \%$ diphenyl $/ 95 \%$ dimethyl polysiloxane as a fixed liquid phase). The column temperature was kept at $50^{\circ} \mathrm{C}$ for $5 \mathrm{~min}$, and then programmed temperature gradient increased to $300^{\circ} \mathrm{C}$ at a rate of $15^{\circ} \mathrm{C}$ per min and kept constant at $300{ }^{\circ} \mathrm{C}$ for $10.5 \mathrm{~min}$. The carrier gas helium passed at a flow rate $54 \mathrm{~mL} / \mathrm{min}$. Injector temperature was $300^{\circ} \mathrm{C}$; sample volume was $1 \mu \mathrm{L}$. Peak areas of the separated compounds were integrated automatically. Mass Spectrum Library 2014 for GSMS (O2125401310) was used to identify the separated compounds by comparing the mass spectra obtained with mass spectra of known compounds stored in the library database. The content of each individual component of the epicuticular waxes was expressed as a percentage of total amounts.

Table 1

Characteristics of the fruit plant species and hybrids of the genus Prumus from the collection of DNU Botanical Garden

\begin{tabular}{|c|c|c|}
\hline Plant species and hybrid forms & Planting date & Hybridization scheme \\
\hline Prumus persica (L.) Batsch & 2012 & - \\
\hline Prunus dulcis (Mill.) D.A.Webb & 2004 & - \\
\hline Hybrid 1 & 2007 & $\mathrm{~F}_{1} 324-87($ P. persica subsp. nucipersica $\times$ Prunus kansuensis $) \times$ F.p. \\
\hline Hybrid 2 & 2004 & $\mathrm{~F}_{1} 1004-88(($ P. persica subsp. nucipersica $\times P$. davidiana $) \times P$. persica subsp. atropurpurea $) \times \mathrm{F} . \mathrm{p}$. \\
\hline Hybrid 3 & 2004 & $\mathrm{~F}_{1} 1004-88(($ P. persica subsp. nucipersica $\times$ P. davidiana $) \times P$. persica subsp. atropurpurea $) \times \mathrm{F}$.p. \\
\hline Hybrid 4 & 2004 & $\mathrm{~F}_{1} 631-89($ P. persica subsp. nucipersica $\times$ P. dulcis $) \times$ F.p. \\
\hline
\end{tabular}

Note: F.p. - free pollination.

Table 2

Assessment of degree of clasterosporium disease in the mature leaves of the genus Prunus species and hybrid forms on a five-point scale $(\mathrm{x} \pm \mathrm{SE})$

\begin{tabular}{|c|c|c|c|c|c|c|}
\hline \multirow{2}{*}{ Damage characteristics } & \multicolumn{6}{|c|}{ Plant species and hybrids } \\
\hline & P.persica & P. dulcis & Hybrid 1 & Hybrid 2 & Hybrid 3 & Hybrid 4 \\
\hline Holes number, pcs. & $2.5 \pm 0.16 a$ & $7.6 \pm 0.63 b$ & $3.2 \pm 0.23 \mathrm{ac}$ & $2.1 \pm 0.04 \mathrm{ac}$ & $12.5 \pm 0.82 \mathrm{~d}$ & $6.9 \pm 0.58 b$ \\
\hline Holes diameter, mm & $3.5 \pm 0.22 \mathrm{a}$ & $2,5 \pm 0.21 \mathrm{ac}$ & $2.5 \pm 0.18 \mathrm{acd}$ & $3.0 \pm 0.06 \mathrm{ad}$ & $4.0 \pm 0.26 \mathrm{ae}$ & $4.5 \pm 0.36 \mathrm{be}$ \\
\hline Leaf surface area, $\mathrm{cm}^{2}$ & $25.6 \pm 1.61 \mathrm{a}$ & $5.8 \pm 0.48 b$ & $23.1 \pm 1.64 \mathrm{a}$ & $37.1 \pm 0.77 \mathrm{c}$ & $44.8 \pm 2.91 \mathrm{~d}$ & $17.1 \pm 1.45 \mathrm{e}$ \\
\hline Damaged leaf area, \% & $0.94 \pm 0.06 \mathrm{a}$ & $6.74 \pm 0.54 b$ & $0.67 \pm 0.05 \mathrm{ac}$ & $0.39 \pm 0.01 \mathrm{ac}$ & $3.56 \pm 0.24 \mathrm{~d}$ & $6.44 \pm 0.62 b$ \\
\hline Disease class & 1 & 3 & 1 & 1 & 2 & 3 \\
\hline
\end{tabular}

Note: the same letters indicate statistically insignificant differences in the means of the compared pair according to the Tukey criterion (HSD).

Determination of wax amount on the leaf surface and GC/MS analysis were performed in three analytical replicates. Average amount of wax deposits was expressed as the mean \pm standard error $(x \pm S E)$. Analyzed parameters such as leaf surface area, damaged area proportion, number and diameter of holes, and the amount of wax deposits were also processed using variance method (ANOVA) factorial experiment, and the dif- ferences between means were tested with Tukey's HSD. Correlation analysis was carried out to assess the relationship between the total amount of leaf epicuticular waxes and content of individual components and the degree of damage to plant leaves. All differences were considered to be statistically significant at $\mathrm{P}<0.05$. 


\section{Results}

Generally, 20 individual compounds belonging to six different classes of hydrocarbons were identified in the chloroform extracts of the epicuticular wax from the adaxial and abaxial surface of the mature leaves of all studied fruit plants. The major class of leaf epicuticular wax component composition was represented by n-alkanes with the even and odd carbon number and chain length varied in the range $\mathrm{C}_{27} \mathrm{C}_{60}$ (Table 3 ).

Alkanes with an even number of carbon atoms in the chain predominated, although detectable amounts of components with an odd number of carbon atoms were also found in leaf waxes of $P$. persica $(4.6 \%)$ and P. dulcis (13.7\%). The total sum of n-alkanes with an even carbon number in the chain varied from $77.6 \%$ to $90.9 \%$ (respectively, in leaf epicuticular waxes of species $P$. dulcis and hybrid 2).

Long-chain n-alkanes 2-methyl-hexacosane $\left(\mathrm{C}_{27} \mathrm{H}_{56}\right)$, pentatriacontane $\left(\mathrm{C}_{35} \mathrm{H}_{72}\right)$, hexatriacontane $\left(\mathrm{C}_{36} \mathrm{H}_{74}\right)$ and tetrapentacontane $\left(\mathrm{C}_{54} \mathrm{H}_{110}\right)$ were represented by several isomers having different retention times. Of these, 2-methyl-hexacosane and pentatriacontane isomers were found only in leaf waxes of plant species $P$. persica and $P$. dulcis but not in the waxes of hybrid forms. By contrast, isomers of hexatriacontane were detected in leaf waxes of hybrids only, while certain tetrapentacontane isomers were present in leaf waxes of all studied fruit plants. The most long-chain n-alkane of all detected in the leaf epicuticular waxes of the plant species and hybrids, hexacontane $\left(\mathrm{C}_{60} \mathrm{H}_{122}\right)$ was found in leaf epicuticular waxes both of $P$. persica and hybrid 4 in almost the same amount (Fig. 1).

Less abundant classes of the hydrocarbons in the composition of leaf epicuticular waxes were the fatty acids, alkenes, primary alcohols, aldehydes, and ethers (Table 4). The share of the remaining unidentified compounds varied from 4 to $12 \%$ in leaf epicuticular waxes of different species and hybrids. Classes of alkenes and aldehydes in the epicuticular waxes of the mature leaves of genus Prunus plants were represented by one compound only, respectively, 17-pentatriacontene and n-octadecanal.

The only aldehyde identified in the chloroform extracts of the adaxial and abaxial leaf epicuticular waxes, octadecanal $\left(\mathrm{C}_{18} \mathrm{H}_{36} \mathrm{O}\right)$, was found in the epicuticular waxes of $P$. dulcis mature leaves (Fig. 2).

Two prime alcohols, 1-tetradecanol and 1-hexacosanol, were found in the epicuticular waxes of mature plant leaves, respectively in hybrid 4 and $P$. dulcis. The ester class contained seven compounds found in leaf epicuticular waxes of both plant species and all hybrid forms. The identification of phthalic acid esters in the wax extracts of plant mature leaves was unexpected (Fig. 3). Total accumulation of the epicuticular wax deposits on the adaxial and abaxial surface of mature plant leaves differed significantly both between species $P$. persica and $P$. dulcis, and hybrid forms as well, and the highest value found for hybrid 2 was twice the minimum wax accumulation for hybrid 4.

Table 3

Composition of n-alkanes detected in the adaxial and abaxial epicuticular waxes of mature leaves of genus Prunus plants (as a percentage of the total, average), and the sum of waxes' accumulation $\left(\mu \mathrm{g} / \mathrm{cm}^{2}\right)$ on leaf surface $(\mathrm{x} \pm \mathrm{SE})$

\begin{tabular}{|c|c|c|c|c|c|c|c|}
\hline \multirow{2}{*}{ Compounds } & \multirow{2}{*}{$\begin{array}{l}\text { Retention } \\
\text { time, min }\end{array}$} & \multicolumn{6}{|c|}{ Plant species and hybrids' names } \\
\hline & & P.persica & P. dulcis & 1 & 2 & 3 & 4 \\
\hline \multirow{2}{*}{ 2-Methyl-Hexacosane $\mathrm{C}_{27} \mathrm{H}_{56}$} & 16.409 & 1.06 & - & - & - & - & - \\
\hline & 21.931 & 3.49 & 1.30 & - & - & - & - \\
\hline \multirow{2}{*}{ Pentatriacontane $\mathrm{C}_{35} \mathrm{H}_{72}$} & 19.058 & - & 8.31 & - & - & - & - \\
\hline & 19.864 & - & 1.27 & - & - & - & - \\
\hline \multirow{4}{*}{ Hexatriacontane $\mathrm{C}_{36} \mathrm{H}_{74}$} & 17.632 & - & - & 12.75 & - & 14.16 & - \\
\hline & 19.028 & - & - & 10.61 & - & - & - \\
\hline & 20.813 & - & - & - & 17.74 & - & - \\
\hline & 23.246 & - & - & - & - & - & - \\
\hline Tetracontane $\mathrm{C}_{40} \mathrm{H}_{82}$ & 17.644 & - & 1.63 & - & 17.44 & - & 6.98 \\
\hline Tetratetracontane $\mathrm{C}_{44} \mathrm{H}_{90}$ & 16.418 & - & 0.41 & - & - & - & - \\
\hline \multirow{5}{*}{ Tetrapentacontane $\mathrm{C}_{54} \mathrm{H}_{110}$} & 17.671 & 9.35 & - & - & - & - & 2.00 \\
\hline & 19.053 & 11.75 & - & - & 19.45 & 16.94 & 17.27 \\
\hline & 20.806 & - & 48.74 & 15.60 & - & 17.63 & 6.63 \\
\hline & 23.339 & 33.10 & 26.82 & 41.56 & 36.23 & 36.61 & 31.41 \\
\hline & 24.822 & 4.28 & - & - & - & - & 2.45 \\
\hline Hexacontane $\mathrm{C}_{60} \mathrm{H}_{122}$ & 20.900 & 19.41 & - & $\begin{array}{llll}- & & & \end{array}$ & - & - & 17.03 \\
\hline Wax deposits' accumulation, $\mu \mathrm{g} / \mathrm{cm}^{2}$ & & $187.8 \pm 11.2^{\mathrm{a}}$ & $170.0 \pm 10.1^{\mathrm{ab}}$ & $119.5 \pm 5.7^{\circ}$ & $240.1 \pm 11.3^{\mathrm{d}}$ & $126.0 \pm 4.9^{\mathrm{e}}$ & $143.8 \pm 8.0^{\mathrm{bec}}$ \\
\hline
\end{tabular}

Note: the same letters indicate statistically insignificant differences in the means of the compared pair according to the Tukey criterion (HSD).

Table 4

Composition of the minor classes of hydrocarbons identified in the adaxial and abaxial epicuticular waxes of mature leaves of genus Prumus plants (as a percentage of the total, average)

\begin{tabular}{|c|c|c|c|c|c|c|c|c|}
\hline \multirow{2}{*}{ Classes } & \multirow{2}{*}{ Compounds } & \multirow{2}{*}{$\begin{array}{l}\text { Retention } \\
\text { time, min }\end{array}$} & \multicolumn{6}{|c|}{ Plant species and hybrid's names } \\
\hline & & & P.persica & P.dulcis & 1 & 2 & 3 & 4 \\
\hline Alkenes & 17-Pentatriacontene & 22.697 & 0.75 & 0.24 & - & - & - & - \\
\hline \multirow[t]{2}{*}{ Alcohols } & 1-tetradecanol & 17.662 & - & - & - & - & - & 2.96 \\
\hline & 1-hexacosanol & 23.445 & - & 1.19 & - & - & - & - \\
\hline Aldehydes & n-Octadecanal & 22.546 & - & 0.14 & - & - & - & - \\
\hline \multirow[t]{2}{*}{ Fatty acids } & Hexadecanoic acid & 14.220 & 0.83 & 1.11 & 1.57 & 0.78 & 0.55 & 1.09 \\
\hline & Octadecanoic acid & 15.560 & 0.92 & 0.26 & 1.34 & 0.63 & 0.46 & - \\
\hline \multirow[t]{7}{*}{ Esters } & 3-Cl-propionic acid heptadesyl ester & 17.651 & - & - & - & - & - & 0.35 \\
\hline & Tetracosanoic acid Methyl ester & 19.307 & - & 0.38 & - & - & - & - \\
\hline & Triacontanoic acid Methyl ester & 21.209 & 2.50 & 2.09 & - & - & 1.17 & - \\
\hline & Nonanoic acid Hexacosyl ester & 19.319 & - & - & - & - & - & 0.59 \\
\hline & Hexacosanoic acid Methyl ester & 21.160 & 0.87 & - & 3.40 & 4.41 & - & - \\
\hline & Phthalic acid di-iso-octyl ester & 18.093 & - & - & - & - & - & 2.10 \\
\hline & Phthalic acid di-n-octyl ester & 18.109 & - & 1.71 & 3.12 & - & - & - \\
\hline \multicolumn{2}{|c|}{ Unidentified compounds ( $\%$ of total) } & & $11.70 \pm 0.27 \mathrm{a}$ & $4.40 \pm 0.22 b$ & $9.91 \pm 0.32 \mathrm{c}$ & $7.01 \pm 0.25 \mathrm{~d}$ & $8.84 \pm 0.31 \mathrm{ce}$ & $9.14 \pm 0.33 \mathrm{ce}$ \\
\hline
\end{tabular}

Note: see Table 3 . 


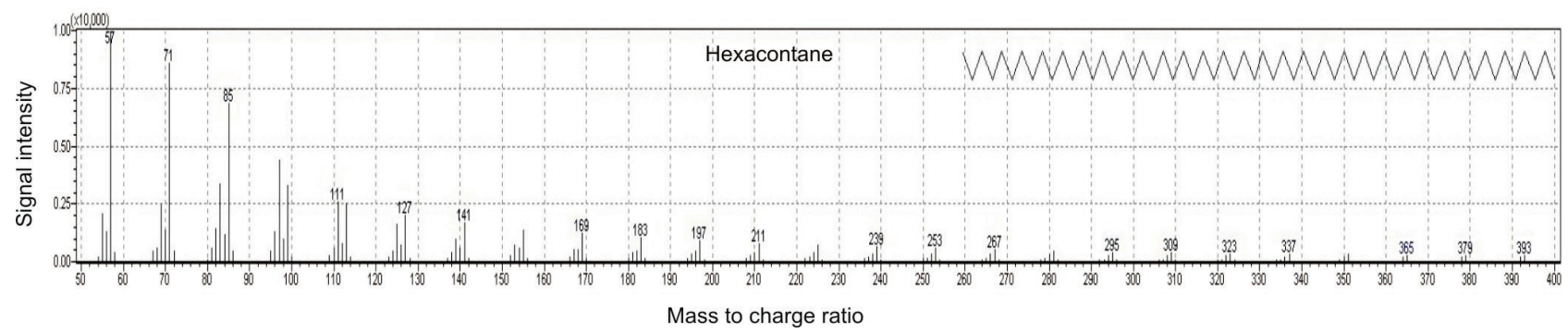

Fig. 1. MS-spectra of hexacontane $\left(\mathrm{C}_{60} \mathrm{H}_{122}\right)$ from the epicuticular waxes of mature leaves of genus Prumus plants

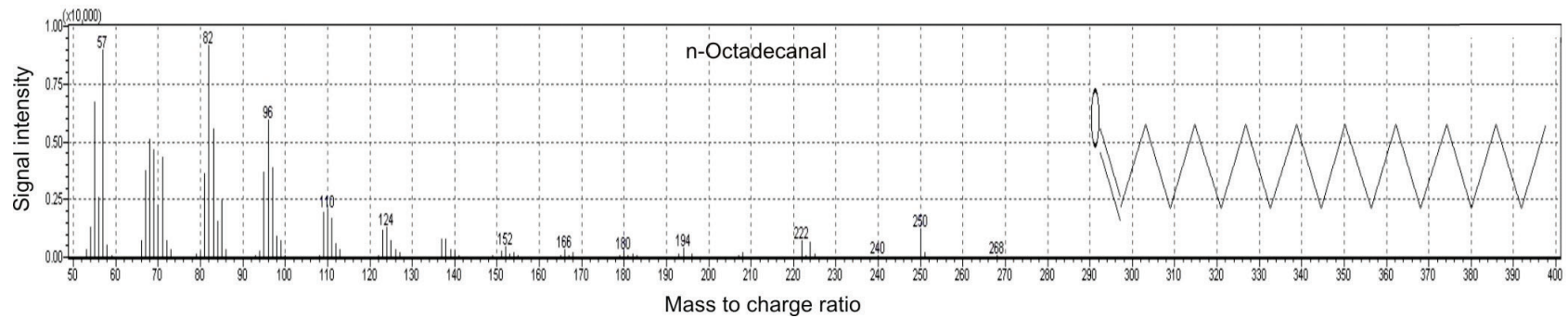

Fig. 2. MS-spectra of octadecyl aldehyde $\left(\mathrm{C}_{18} \mathrm{H}_{36} \mathrm{O}\right)$ identified in leaf epicuticular waxes of Prunus dulcis

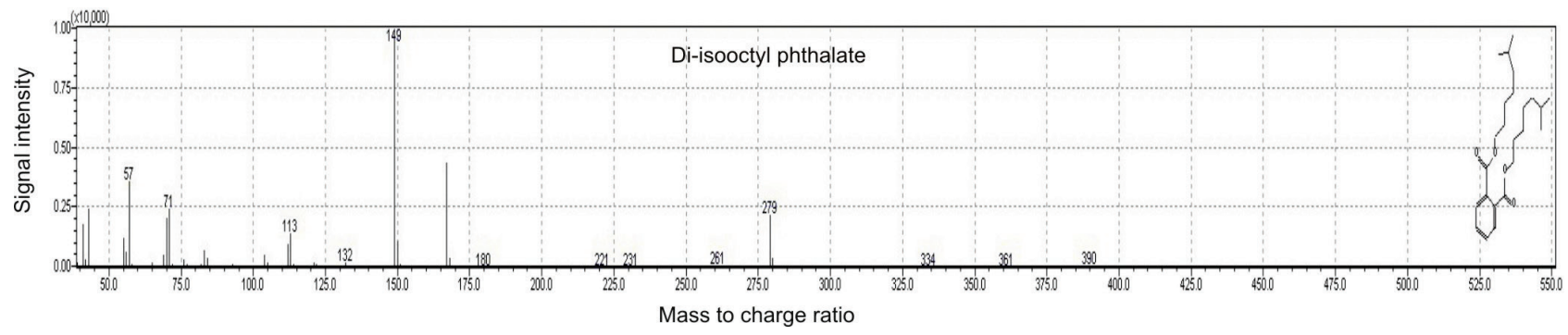

Fig. 3. MS-spectra of di-isooctyl phthalate $\left(\mathrm{C}_{24} \mathrm{H}_{38} \mathrm{O}_{4}\right)$ identified in the chloroform extracts of the adaxial and abaxial leaf epicuticular waxes of hybrid 4

Correlation analysis showed no significant relationship between the total amount of epicuticular waxes on mature leaf surface of genus Prunus plants and leaf resistance to clasterosporium disease $(r=-0.56 \pm 0.41$ for number of holes, and $r=-0.32 \pm 0.47$ for damaged leaf area). At the same time, the content of tetrapentacontane (the sum of all isomers, \%) in leaf waxes was significantly positively correlated with indicators of plant sensitivity to clasterosporium $(\mathrm{r}=0.77 \pm 0.16, \mathrm{P}=0.0002$ for number of holes, and $\mathrm{r}=0.81 \pm 0.15, \mathrm{P}=0.0001$ for damaged leaf area).

\section{Discussion}

The total quantity of epicuticular wax extracted from both the adaxial and abaxial leaf surface of the genus Prumus plants varied markedly, and the wax deposits in species $P$. persica and $P$. dulcis were larger than in hybrid forms, except for hybrid 2 . However, there was no statistically significant correlation between the total leaf waxes' yield and clasterosporium disease damage of the mature leaves of plants. Our findings on variability of the epicuticular waxes' accumulation by plants belonging to the same genus agree with previously established differences for woody plants (Lykholat et al., 2018), and with the known data as well. According to the results of Maiti et al. (2016) studying the variation of wax quantity in 35 plant species, the wax amount can vary from $11.18 \mu \mathrm{g} / \mathrm{cm}^{2}$ (Amyris texana (Buckley) P. Wilson)) to $702.04 \mu \mathrm{g} / \mathrm{cm}^{2}$ (Forestiera angustifolia Torr.). Khan et al. (2015) showed that on the leaves of different cotton varieties, the maximum amount of wax reached $183 \mu \mathrm{g} / \mathrm{cm}^{2}$, while the minimum was $95 \mu \mathrm{g} / \mathrm{cm}^{2}$. Notable differences based on concentration and composition of cuticular wax were identified by Klavins \& Klavins (2020) between different blueberry species and varieties.

Epicuticular wax composition both in mature leaves of species $P$. persica and $P$. dulcis, and the hybrid forms was almost absolutely dominated by the long-chain n-alkanes, which is consistent with the known data for many plant species. The predominance of long-chain n-alkanes in the epicuticular waxes was reported by Gniwotta et al. (2005) for the abaxial surface of Pisum sativum L. leaves, Kim et al. (2007) for the leaves of Sesamum indicum L., by Van Maarseveen \& Jetter (2009) for Kalanchoe daigremontiana Hamet \& H. Perrier leaves, and Lykholat et al. (2018) for Tilia species leaves. An explanation of this pattern can be contained in the assumption of Fernández et al. (2016) that the non-polar compounds with low solubility, such as alkanes, can migrate from the cell wall to the epicuticular wax layer, while the polar compounds (i.e. alcohols, acids, esters) having the hydrogen bonds, will be held in the inner layer of the cuticular waxes.

Confirming the general tendency, Buschhaus \& Jetter (2012) reported the high quantity of long-chain n-alkanes (35.5\% of total waxes sum) in the epicuticular waxes of Arabidopsis leaves with the predominance of compounds with odd carbon numbers ( $49 \%$ of the alkane fraction). However, our study results showed a dissimilar pattern characterized by the presence of a relatively small amount of odd carbon number alkanes only in the waxes of $P$. persica and $P$. dulcis, and the absence of these compounds in the wax of hybrids. Thus, our results are in contrast to known data (Medina et al., 2006) about n-nonacosane $\left(\mathrm{C}_{29}\right)$ and n-hentriacontane $\left(\mathrm{C}_{31}\right)$ as the widest spread n-alkanes in the waxes oh high plants. These differences may be due to both the specificity of epicuticular wax composition of different plant species, and leaf age as well, taking into account the mature leaves of the studied genus Prumus plants. The age-dependent increase in the abundance of long-chain n-alkanes (more than $\mathrm{C}_{30}$ ) was found by Bourgault et al. (2020) in developing leaves of maize with a maximum accumulation at the end of cuticle formation.

In the present study, the statistically significant correlation $(\mathrm{P}<0.001)$ between the GC-MS data of the identified components of leaf epicuticular waxes and the estimated leaf damage with clasterosporium disease was found only for tetrapentacontane content (sum of all isomers), while an insignificant relationship was established in all other cases. The role of long-chain n-alkanes in the development of fungal pathogenesis has not yet been determined unambiguously, and is evaluated in different ways, sometimes from opposite positions. At early stage of wheat infection by fungus Blumeria graminis (DC.) Speer secreting lipase to the leaf surface was shown the release of epicuticular wax components, among which 
long-chain alkanes were assigned the role of a signal that triggers mycelium modifications and contributes to pathogen development and infection (Feng et al., 2009). On the other hand, Gniwotta et al. (2005) studying the early events in the interaction of pea (Pisum sativum L.) leaves with hostspecific pathogenic fungi Erysiphe pisi DC., established significantly lower germination efficiencies and appressoria formation rates on the abaxial leaf surfaces, where the alkanes (mainly hentriacontane, 63\%) dominated. Similarly, Hansjakob et al. (2010) argue that during in vitro experiments such components of wheat and barley cuticular wax as alkanes, fatty acids and alkyl esters, did not affect the prepenetration of the barley powdery mildew fungus (Blumeria graminis f. sp. hordei). Since in our work the plant leaves of the genus Prumus species were studied at the terminal stage of infection with the fungus Clasterosporium carpohilum Lev. Aderh., a positive correlation between the level of leaf damage and the content of tetrapentacontane in epicuticular waxes could presumably be the result of a metabolism rearrangement in the epidermal cells of infected leaves. Infection-induced reprogramming of carbohydrate and lipid metabolisms was identified by Agudelo-Romero et al. (2015) in grape berries infected with Botrytis cinerea Pers., and led to an increased regulation of genes associated with lipid and wax biosynthesis and the accumulation of saturated long-chain fatty acids. Thus, elucidating the role of tetrapentacontane as a protective component of genus Prunus plants or as an accomplice of a pathogenic fungus requires further study.

Our results of correlation analysis are in stark contrast to the significant correlation established by Batovska et al. (2009) for 10 individual components of the epicuticular waxes of grapevine leaves affected by downy mildew (Plasmopara viticola (Berk. \& M. A. Curtis) Berl. \& De Toni). At the same time, our findings confirm the cited authors' conclusion that the more polar cuticular wax compounds were related to sensitivity of plant leaves to the pathogenic fungal action. It can be assumed that a higher degree of infection of $P$. dulcis leaves with clasterosporiosis may be associated with the presence in the epicuticular waxes of 1-hexacosanol and $\mathrm{C}_{18}$-aldehyde octadecanal, which are absent in leaf epicuticular wax of the more resistant species $P$. persica. Similar conclusions about the trigger function of very-long-chain aldehydes, in particular, $\mathrm{C}_{26}$-aldehyde $\mathrm{n}$ hexacosanal (Tsuba et al., 2002; Hansjakob et al., 2011) were based on the study results of conidial germination and differentiation of powdery mildew fungus (Blumeria graminis f. sp. hordei) on the leaves of host plant barley (Hordeum vulgare L.). In addition, Ringelmann et al. (2009) found that the absence of $\mathrm{C}_{26}$-aldehyde in abaxial epicuticular waxes of ryegrass (Lolium perenne L.) leaves disrupts the development of the fungus Blumeria graminis (DC.) Speer. However, Tsuba et al. (2002) found that for non-host plants such as tobacco, the content of $\mathrm{C}_{26}$ aldehyde in waxes is not a determining factor of infection by $B$. graminis (DC.) Speer, or, as in cabbage leaves, aldehydes with $\mathrm{C}_{28}$ and $\mathrm{C}_{30}$ chain lengths dominate.

The identification of phthalic acid esters in wax extracts from leaf surface of the genus Prunus plants has raised questions about the origin of the compounds found. Phthalates have traditionally been considered artificially synthesized compounds that are widely used in various fields of human activity, simultaneously polluting the air and water bodies. However, recent studies (Babu \& Wu, 2010) have provided the direct evidence of di(n-butyl) phthalate and mono(2-ethylhexyl) phthalate biosynthesis by freshwater micro-algae and cyanobacteria from labeled precursors. Tian et al. (2016) found that the fungal generation of di-n-butyl phthalate was largely through the shikimic acid pathway, which was assembled by phthalic acid with butyl alcohol through esterification. Bis(2-ethylhexyl)phthalate was identified in leaf extracts of Sansevieria roxburghiana Schult. \& Schult. f. (Philip et al., 2011) and Lavandula officinalis Chaix (Shafaghat et al., 2012). In chloroform extracts of leaf waxes of the genus Prumus plants, di-n-octyl phthalate and di-isooctyl phthalate were identified, respectively in $P$. dulcis and hybrid 1, and hybrid 4 leaves. Obviously, the results obtained do not give an unambiguous answer either about the endogenous origin of phthalates or about the absorption of these compounds from the environment. However, given the differences in the distribution of several phthalic acid esters in the wax extracts of leaves and fruits of closely growing trees, there is reason to assume the possibility of biosynthesis of the detected phthalates.

\section{Conclusions}

Differences in the resistance of the genus Prunus species and hybrids to clasterosporium disease were not statistically significantly correlated with total amount of the epicuticular wax deposits on the adaxial and abaxial surface of mature leaves. Almost absolutely domination in leaf waxes of both species and hybrids by long-chain n-alkanes coincided with known data for many plant species. However, the predominance of $\mathrm{n}$ alkanes with an even carbon number was in stark contrast to the published data, and can be explained not so much by the species as by the age specificity of the epicuticular waxes' composition of mature leaves of the studied plants. It can be assumed that a higher degree of infection of $P$. dulcis leaves with clasterosporiosis may be associated with the presence in the epicuticular waxes of 1-hexacosanol and $\mathrm{C}_{18}$-aldehyde octadecanal, which are absent in leaf epicuticular wax of more resistant species $P$. persica. Strong positive correlation between the degree of clasterosporium disease manifestation and the tetrapentacontane content in mature leaf waxes does not allow one to judge the function of these alkanes in the early stages of plant leaves' infection. So, elucidating the role of tetrapentacontane as a protective component of the genus Prumus plants or as an accomplice of the pathogenic fungus Clasterosporium carpohilum Lev. Aderh. requires the study of the earlier infection stages.

This work was supported by the Ministry of Education and Science of Ukraine (grant number 0116U001526).

\section{References}

Agudelo-Romero, P., Erban, A., Rego, C., Carbonell-Bejerano, P., Nascimento, T., Sousa, L., Martínez-Zapater, J. M., Kopka, J., \& Fortes, A. M. (2015). Transcriptome and metabolome reprogramming in Vitis vinifera cv. trincadeira berries upon infection with Botrytis cinerea. Journal of Experimental Botany, 66, 1769-1785.

Azmy, A., \& Korra, A. (2010). Management of shot-hole disease of stone fruit trees caused by Stigmina carpophila. Journal of Plant Protection and Pathology, 1(12), 973-989.

Babu, B., \& Wu, J.-T. (2010). Production of phthalate esters by nuisance freshwater algae and cyanobacteria. Science of the Total Environment, 408(21), 4969 4975 .

Baranovski, B., Khromykh, N., Karmyzova, L., Ivanko, I., \& Lykholat, Y. (2016). Anyalysis of the alien flora of Dnipropetrovsk province. Biological Bulletin of Bogdan Chmelnitskiy Melitopol State Pedagogical University, 6(3), 419-429.

Batovska, D. I., Todorova, I. T., \& Popov, S. S. (2009). Seasonal variations in the leaf surface composition of field grown grapevine plants. Journal of the Serbian Chemical Society, 74, 1229-1240.

Bohinc, T., Markovic, D., \& Trdan, S. (2014). Leaf epicuticular wax as a factor of antixenotic resistance of cabbage to cabbage flea beetles and cabbage stink bugs attack. Acta Agriculturae Scandinavica, Section B - Soil and Plant Science, 64(6), 493-500.

Bourgault, R., Matschi, S., Vasquez, M., Qiao, P., Sonntag, A., Charlebois, C., Mohammadi, M., Scanlon, M. J., Smith, L. G., \& Molina, I. (2020). Constructing functional cuticles: Analysis of relationships between cuticle lipid composition, ultrastructure and water barrier function in developing adult maize leaves. Annals of Botany, 125, 79-91.

Braccini, C. L., Vega, A. S., Aroz, M. V. C., Teal, P. E., Cerrillo, T., Zavala, J. A., \& Fernandez, P. C. (2015). Both volatiles and cuticular plant compounds determine oviposition of the willow sawfly Nematus oligospilus on leaves of Salix spp. (Salicaceae). Joumal of Chemical Ecology, 41, 985-996.

Buschhaus, C., Herz, H., \& Jetter, R. (2007). Chemical composition of the epicuticular and intracuticular wax layers on adaxial sides of Rosa canina leaves. Annals of Botany, 100(6), 1557-1564.

Buschhaus, C., \& Jetter, R. (2012). Composition and physiological function of the wax layers coating Arabidopsis leaves: b-Amyrin negatively affects the intracuticular water barrier. Plant Physiology, 160, 1120-1129.

Calvo-Garrido, C., Elmer, P. A., Parry, F. J., Viñas, I., Usall, J., Torres, R., Agnew, R. H., \& Teixidó, N. (2014). Mode of action of a fatty acid-based natural product to control Botrytis cinerea in grapes. Journal of Applied Microbiology, 116,967-979.

Dar, R. A., Rai, A. N., \& Shiekh, I. A. (2017). Stigmina carpophila detected on Prunus armeniaca and Prunus persica in India. Australasian Plant Disease Notes, 12, 19.

Ding, S., Zhang, J., Yang, L., Wang, X., Fu, F., Wang, R., Zhang, Q., \& Shan, Y. (2020). Changes in cuticle components and morphology of 'Satsuma' mandarin 
(Citrus unshiu) during ambient storage and their potential role on Penicillium digitatum infection. Molecules, 25(2), 412.

Feng, J., Wang, F., Liu, G. S., Greenshields, D., Shen, W. Y., Kaminskyj, S., Hughes, G. R., Peng, Y. L., Selvaraj, G., Zou, J. T., \& Wei, Y. (2009). Analysis of a Blumeria graminis-secreted lipase reveals the importance of host epicuticular wax components for fungal adhesion and development. Molecular PlantMicrobe Interactions, 22, 1601-1610.

Fernández, V., Guzmán-Delgado, P., Graça, J., Santos, S., \& Gil, L. (2016). Cuticle structure in relation to chemical composition: Re-assessing the prevailing model. Frontiers in Plant Science, 7, 427.

Gniwotta, F., Vogg, G., Gartmann, V., Carver, T. L. W., Riederer, M., \& Jetter, R. (2005). What do microbes encounter at the plant surface? Chemical composition of pea leaf cuticular waxes. Plant Physiology, 139, 519-531.

Hansjakob, A., Bischof, S., Bringmann, G., Riederer, M., \& Hildebrandt, U. (2010). Very long chain aldehydes promote in vitro prepenetration processes of Blumeria graminis in a dose and chain length dependent manner. New Phytologist, 188, 1039-1054.

Hansjakob, A., Riederer, M., \& Hildebrandt, U. (2011). Wax matters: Absence of very-long-chain aldehydes from the leaf cuticular wax of the glossy11 mutant of maize compromises the prepenetration processes of Blumeria graminis. Plant Pathology, 60, 1151-1161.

Jetter, R., \& Riederer, M. (2016). Localization of the transpiration barrier in the epiand intracuticular waxes of eight plant species: Water transport resistances are associated with fatty acyl rather than alicyclic components. Plant Physiology, 170,921-934.

Khan, M. A. U., Shahid, A. A., Rao, A. Q., Bajwa, K. S., Muzaffar, A., Rehman Samiullah, T., \& Husnain, T. (2015). Molecular and biochemical characterization of cotton epicuticular wax in defense against cotton leaf curl disease. Iranian Journal of Biotechnology, 13(4), 3-9.

Kim, K. S., Park, S. H., \& Jenks, M. A. (2007). Changes in leaf cuticular waxes of sesame (Sesamum indicum L.) plants exposed to water deficit. Journal of Plant Physiology, 164(9), 1134-1143.

Klavins, L., \& Klavins, M. (2020). Cuticular wax composition of wild and cultivated Northern Berries. Foods, 9(5), 587.

Koch, K., \& Ensikat, H. J. (2008). The hydrophobic coatings of plant surfaces: Epicuticular wax crystals and their morphologies, crystallinity and molecular self-assembly. Micron, 39(7), 759-772.

Łaźniewska, J., Macioszek, V. K., \& Kononowicz, A. K. (2012). Plant-fungus interface: The role of surface structures in plant resistance and susceptibility to pathogenic fungi. Physiological and Molecular Plant Pathology, 78, 24-30.

Lee, S. B., \& Suh, M. C. (2015). Advances in the understanding of cuticular waxes in Arabidopsis thaliana and crop species. Plant Cell Reports, 34(4), 557-572.

Lykholat, Y. V., Khromykh, N. O., Pirko, Y. V., Alexeyeva, A. A., Pastukhova, N. L., \& Blume, Y. B. (2018). Epicuticular wax composition of leaves of Tilia L. trees as a marker of adaptation to the climatic conditions of the Steppe Dnieper. Cytology and Genetics, 52(5), 323-330.

Maiti, R., Rodriguez, H. G., Gonzalez, E. A., Kumari, A., \& Sarkar, N. C. (2016). Variability in epicuticular wax in 35 woody plants in Linares, Northeast Mexico. Forest Research, 5, 162.

Medina, E., Aguiar, G., Gomez, M., Aranda, J., Medina, J. D., \& Winter, K. (2006). Taxonomic significance of the epicuticular wax composition in species of the genus Clusia from Panama. Biochemical Systematics and Ecology, 34, 319-326.

Nanni, V., Zanetti, M., Bellucci, M., Moser, C., Bertolini, P., Guella G., Dalla Serra, M., \& Baraldi, E. (2013). The peach (Prunus persica) defensin PpDFN1 displays antifungal activity through specific interactions with the membrane lipids. Plant Pathology, 62(2), 393-403.

Nazarenko, M., Lykholat, Y., Grigoryuk, I., \& Khromykh, N. (2018). Optimal doses and concentrations of mutagens for winter wheat breeding purposes. Part I. Grain productivity. Journal of Central European Agriculture, 19(1), 194-205.

Nazarenko, M., Khromykh, N., Matyukha, V., Lykholat, Y., Bezus, R., \& Shupranova, L. (2019). Chemical plant protection agents change the yield structure and the grain quality of winter wheat (Triticum aestivum L.). Bulletin of Transilvania University of Brasov - series II - Forestry, Wood Industry, Agricultural, Food Engineering, 12(2), 97-106.

Niks, R. E., \& Rubiales, D. (2002). Potentially durable resistance mechanisms in plants to specialized fungal pathogens. Euphytica, 124, 201-216.

Palchykov, V., Khromykh, N., Lykholat, Y., Mykolenko, S., \& Lykholat, T. (2019). Synthesis and plant growth regulatory activity of 3-sulfolene derivatives. Chemistry and Chemical Technology, 13(4), $424-428$.

Philip, D., Kaleena, P. K., \& Valivittan, K. (2011). GC-MS analysis and antibacterial activity of chromatographically separated pure fractions of leaves of Sansevieria roxburghiana. Asian Journal of Pharmaceutical and Clinical Research, 4(4), 130-133.

Rebora, M., Salemo, G., Piersanti, S., Gorb, E., \& Gorb, S. (2020). Role of fruit epicuticular waxes in preventing Bactrocera oleae (Diptera: Tephritidae) attachment in different cultivars of Olea europaea. Insects, 11, 189.

Ringelmann, A., Riedel, M., Riederer, M., \& Hildebrandt, U. (2009). Two sides of a leaf blade: Blumeria graminis needs chemical cues in cuticular waxes of Lolium perenne for germination and differentiation. Planta, 230, 95-105.

Shafaghat, A., Salimi, F., \& Amani-Hooshyar, V. (2012). Phytochemical and antimicrobial activities of Lavandula officinalis leaves and stems against some pathogenic microorganisms. Journal of Medicinal Plants Research, 6(3), 455-460.

Sharma, P., Kothari, S. L., Rathore, M., \& Gour, V. (2018). Properties, variations, roles, and potential applications of epicuticular wax: A review. Turkish Journal of Botany, 42, 135-149.

Shcherbyna, R. O., Danilchenko, D. M., Parchenko, V. V., Panasenko, O. I., Knysh, E. H., Khromykh, N. O., \& Lykholat, Y. V. (2017). Studying of 2-((5-R-4-R14H-1,2,4-triazole-3-yl)thio)acetic acid salts influence on growth and progress of blackberries (KIOWA Variety) propagules. Research Journal of Pharmaceutical, Biological and Chemical Science, 8, 975-979.

Sivankalyani, V., Feygenberg, O., Diskin, S., Wright, B. S., \& Alkan, N. (2016). Increased anthocyanin and flavonoids in mango fruit peel are associated with cold and pathogen resistance. Postharvest Biology and Technology, 111, 132-139.

Tian, C., Ni, J., Chang, F., Liu, S., Nan, X., Sun, W., Xie, Y., Guo, Y., Ma, Y., Yang, Z., Dang, C., Huang, Y., Tian, Z., \& Wang, Y. (2016.) Bio-source of di-n-butyl phthalate production by filamentous fungi. Scientific Reports, 6, 19791.

Trivedi, P., Nguyen, N., Hykkerud, A. L., Häggman, H., Martinussen, I., Jaakola, L., \& Karppinen, K. (2019). Developmental and environmental regulation of cuticular wax biosynthesis in fleshy fruits. Frontiers in Plant Science, 10, 431.

Tsuba, M., Katagiri, C., Takeuchi, Y., Takada, Y., \& Yamaoka, N. (2002). Chemical factors of the leaf surface involved in the morphogenesis of Blumeria graminis. Physiological and Molecular Plant Pathology, 60, 51-57.

Wen, M., Buschhaus, C., \& Jetter, R. (2006). Nanotubules on plant surfaces: Chemical composition of epicuticular wax crystals on needles of Taxus baccata L. Phytochemistry, 67(16), 1808-1817.

Van Maarseveen, C., \& Jetter, R. (2009). Composition of the epicuticular and intracuticular wax layers on Kalanchoe daigremontiana (Hamet et Perr. de la Bathie) leaves. Phytochemistry, 70(7), 899-906.

Yeats, T. H., \& Rose, J. K. C. (2013). The formation and function of plant cuticles. Plant Physiology, 163, 5-20.

Zabka, V., Stangl, M., Bringmann, G., Vogg, G., Riederer, M., \& Hildebrandt, U. (2008). Host surface properties affect prepenetration processes in the barley powdery mildew fungus. New Phytologist, 177(1), 251-263.

Zacchino, S. A., Butassi, E., Liberto, M. D., Raimondi, M., Postigo, A., \& Sortino, M. (2017). Plant phenolics and terpenoids as adjuvants of antibacterial and antifungal drugs. Phytomedicine, 37, 27-48.

Zazharskyi, V. V., Davydenko, P. O., Kulishenko, O. M., Borovik, I. V., Kabar, A. M., \& Brygadyrenko, V. V. (2020). Anti-bacterial and fungicidal effect of ethanol extracts from Juniperus sabina, Chamaecyparis lawsoniana, Pseudotsuga menziesii and Cephalotaxus harringtonia. Regulatory Mechanisms in Biosystems, 11(1), 105-109. 